\title{
Dynamic analysis of railway track with vibration isolated booted sleepers
}

\author{
Vladimir Smirnov ${ }^{1, *}$ \\ ${ }^{1}$ Moscow State University of Civil Engineering, Yaroslavskoe shosse, 26, Moscow, 129337, Russia
}

\begin{abstract}
The article deals with dynamic analysis of a railway track in a tunnel or on surface. Instead of concrete sleepers, booted ones are used, with additional under-sleeper pad made of elastomeric material. Introduction of additional elasticity in the railway track increases both the track elasticity and resultant service life and has some vibration isolation effect. Using the infinite length beam model with Winkler supports, the insertion loss of such a system is studied and appropriate pad stiffness is derived that can effectively reduce vibration arising from the railway track. Finite element (FE) model of the track is created in MSC Patran/Nastran software package, that helps to get an insight on the track behaviour under dynamic train excitation. Finally, both the analytical and FE models are verified with the measurement results obtained from an experimental modal analysis of an underground railway track with booted sleepers and polyurethane sleeper pads.
\end{abstract}

\section{Introduction}

Transport infrastructure of large cities is impossible without the presence of railway transport : trams, inercity or commuter trains or the most efficient type of mass transport the underground, with its greatest people-carrying ability. The development of the railway lines "bites" into the existing planned urban areas together with the decrease of the areas for new construction, not affected by anthropogenic activity from the subway.

It is well known, that the railway lines appears to be the sources of significant vibrations that spreads through the soil and transfers to the building's foundation that are located near the railway track (at a distance less than $100 \mathrm{~m}$ ) [1]. These vibrations then spreads through the load-bearing structures of a building and produce vibrations of walls and floors, that influence both the technical state of the building and sanitary-hygienic conditions of human stay. The vibration generated inside the premises of residential and public areas due to train traffic has unsteady discontinuous character with a marked predominance of signal in the frequency band of $4-125 \mathrm{~Hz}$, and repeats with a period determined by the schedule of train passes.

Various methods have been designed and utilized to reduce the level of train-induced vibrations $[2,3,5]$. These methods are classified as follows: vibration reduction at a source, preventing further propagation of vibrations on the path, and reducing vibrations at the

\footnotetext{
* Corresponding author: belohvost@list.ru
} 
receiver by means of building' vibration isolation system [2]. The article deals with one of the solutions that is of major interest in the rail sector - use of special rubber or elastomeric pads beneath the sleepers [4]. These pads, which are generally called under sleeper pads (USPs) are shown in Figure 1, find extensive application in railway tracks and have several advantages such as [4]: improved track quality, reduced maintenance and life cycle costs [6]; smaller stress applied to track components, ability to reduce ballast depth and more uniform distribution of loads; smaller corrugations with long wavelengths in small curves [7]; very gradual change in track stiffness at transition zones and turnout regions [8]; smaller train-induced vibrations in the ground and surrounding structures [9], etc.

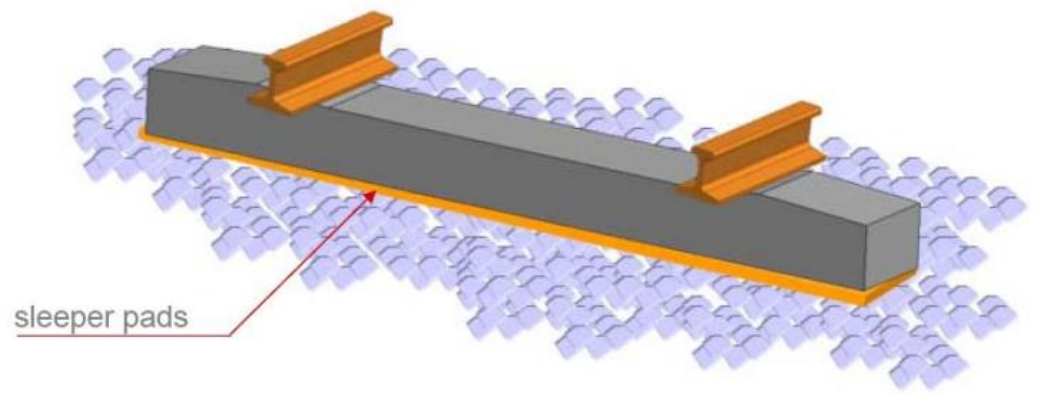

Fig. 1. Under sleeper pad.

Many theoretical studies and some field trials in Austria and France suggest that the added resiliency by USPs will attenuate impact and excessive vibration [10]. Consequently, it is worthwhile to trial such technology in problematic areas, for example at locations with rail surface defects, dipped joints, spark erosions, or other discontinuities in rail running surface.

Another type of USPs used in slab tracks instead of the ballasted one are the booted sleepers as shown in Figure 2. The elastomeric pad is placed beneath the single concrete block ( $1 / 2$ of the sleeper's width), block and resilient pad are covered in a rubber boot, that simplifies erection and maintenance.

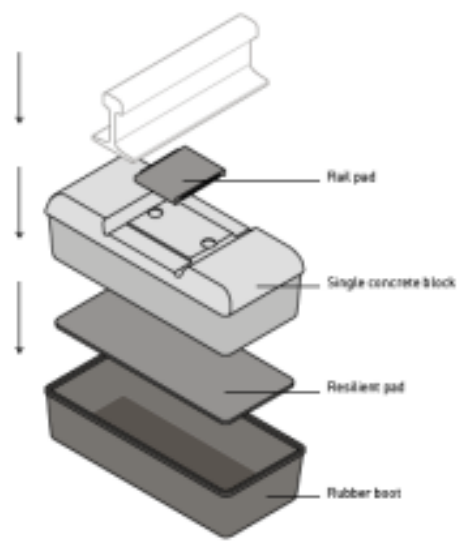

Fig. 2. Booted sleeper' structure.

Due to spreading of these solutions in railway engineering the problem of track dynamic analysis with resilience pads installed beneath the sleepers plays a major role. Mentioned problems state the task of developing a robust method to predict dynamic response of the booted sleepers or sleepers with USPs. 


\section{Analytical model}

The vertical behaviour of sleepers has been studied for many years using a beam supported by a constant ballast pressure (ORE D71 RP9, UIC713). The introduction of resilient elements in the track (rail pads, USP's, sleeper boots) has led to the need to develop suitable methods for the determination of track deflection and vibration attenuation properties.

Usually the track is modelled as a beam (rail) laying on an elastic Winkler foundation [11] - generally abbreviated to "BOEF". This concept is illustrated in Figure 3, which also shows a series of moving loads $\mathrm{F}$ (train axes).

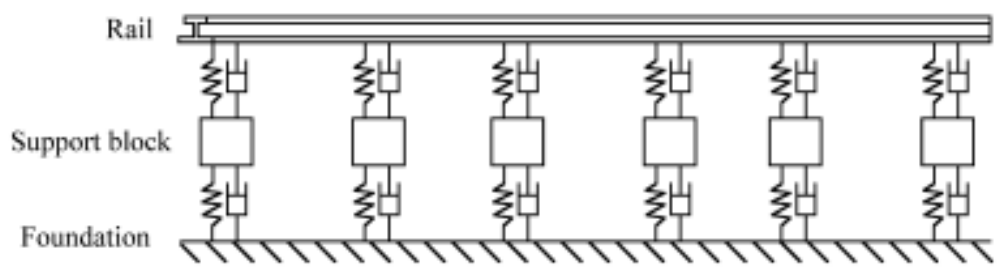

Fig. 3. Infinite beam on elastic Winkler foundation.

The rail support may be further separated, as shown in Figure 3, into rail fastening element (primarily spring with the railpad stiffness), the mass element (weight of the concrete block or the sleeper), undersleeper element (spring with the elastic pad stiffness) and spring element below the sleepers (arising from the ballast, sub-ballast and subgrade).

Quasi-static rail displacement $\mathrm{w}(0, \mathrm{t})$ at a time $\mathrm{t}=0$ and at a reference point $\mathrm{x}=0$, resulting from a series of $n$ loads $F_{n}$ each at a distance of $d_{n}$ from the reference point, all moving with the same velocity $\mathrm{v}$, as shown in:

$$
w(0, t)=\sum_{n=1}^{N} \frac{F_{n}}{2 k L} e^{-\frac{u-d_{0}}{L}}\left[\cos \left(\frac{v t-d_{n}}{L}\right)+\sin \left(\frac{v t-d_{n}}{L}\right)\right]
$$

where $\mathrm{w}(\mathrm{x}, \mathrm{t})$ is vertical displacement, $\mathrm{k}$ is the support system modulus $(\mathrm{N} / \mathrm{m} / \mathrm{m})$, EI is the bending stiffness of the rail $\left(\mathrm{Nm}^{2}\right)$ and $L=\sqrt[4]{\frac{4 E I}{U}}$ is characteristic length.

One of the main dynamic properties is the eigenfrequency of the system which is calculated by the formula :

$$
f_{0}=\frac{1}{2 \pi} \sqrt{\frac{\beta}{m_{e f f}}}
$$

where $\beta-$ is track stiffness, which is calculated using formula: $\beta=2 \sqrt[4]{4 E I \cdot U^{3}} ; \mathrm{m}_{\text {eff }}-$ effective mass of the system.

Effective mass of the system consists of the rail weight, axes weight and sleepers weight on the deflection curve length $1, l=\frac{\beta}{U}$.

The stiffness of the rail support and stiffness of its elements are related using equation:

$$
\frac{1}{k_{\text {support }}}=\sum \frac{1}{k_{\text {element }}}
$$

where $k_{\text {element }}-$ stiffness of the support elements. 
Using Eq. (2), the vibration isolation effect or insertion loss for the system can be calculated as degree of vibration transmission (in $\mathrm{dB}$ ) for one-degree-of-freedom system:

$$
L(f)=20 \cdot \log \left[\sqrt{\frac{1+\eta^{2}\left(\frac{f}{f_{0}}\right)^{2}}{\left(1-\left(\frac{f}{f_{0}}\right)^{2}\right)^{2}+\eta^{2}\left(\frac{f}{f_{0}}\right)^{2}}}\right]
$$

Table 1 presents the data for the track with LVT-M and LVT-HA booted sleepers [12].

Table 1. Track properties with booted sleepers.

\begin{tabular}{|c|c|c|}
\hline \multirow{2}{*}{ Property } & \multicolumn{2}{|c|}{ Value } \\
\cline { 2 - 3 } & $L V T-M$ & LVT-HA \\
\hline Railpad stiffness & $150 \mathrm{kN} / \mathrm{mm}$ & $150 \mathrm{kN} / \mathrm{mm}$ \\
\hline Sleeper pad stiffness & $25 \mathrm{kN} / \mathrm{mm}$ & $15 \mathrm{kN} / \mathrm{mm}$ \\
\hline Block weight & $59 \mathrm{~kg}$ & $116 \mathrm{~kg}$ \\
\hline Deflection curve length & $2,1 \mathrm{~m}$ & $2,5 \mathrm{~m}$ \\
\hline Effective mass & $1645 \mathrm{~kg}$ & $2362 \mathrm{~kg}$ \\
\hline
\end{tabular}

Insertion loss for two track types is plotted in Figure 4 using data in Table 1 and Eq. (4).

a)

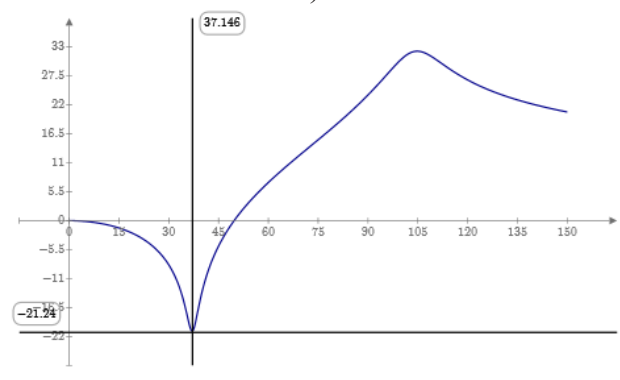

$\underline{\omega}$ b)

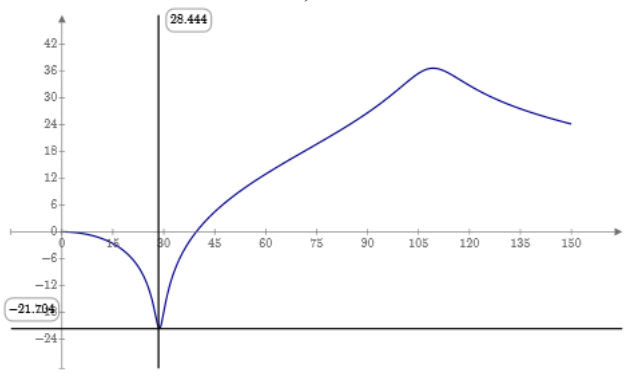

$\omega$

Fig. 4. Insertion loss for the track with LVT-M (a) and LVT-HA (b).

\section{Finite element model}

In order to get a deeper insight into the track behavior with resilient elements, the finite element (FE) model of the track is created using MSC Patran/Nastran commercial FE package. The model consists of the rails, simulated using 1-D beam elements, intermediate railway fastenings, simulated using DOF - spring elements with prescribed stiffness and damping, intermediate masses, simulated using 0-D mass elements and undersleeper pads, simulated using DOF - spring elements with prescribed stiffness and damping. In order to simulate beam of infinite length, the symmetry boundary conditions are applied at each end 
of the rail. The model is loaded with a two-wheel boogie with 15 to axle load. FE-model ready for analysis is shown in Figure 5.

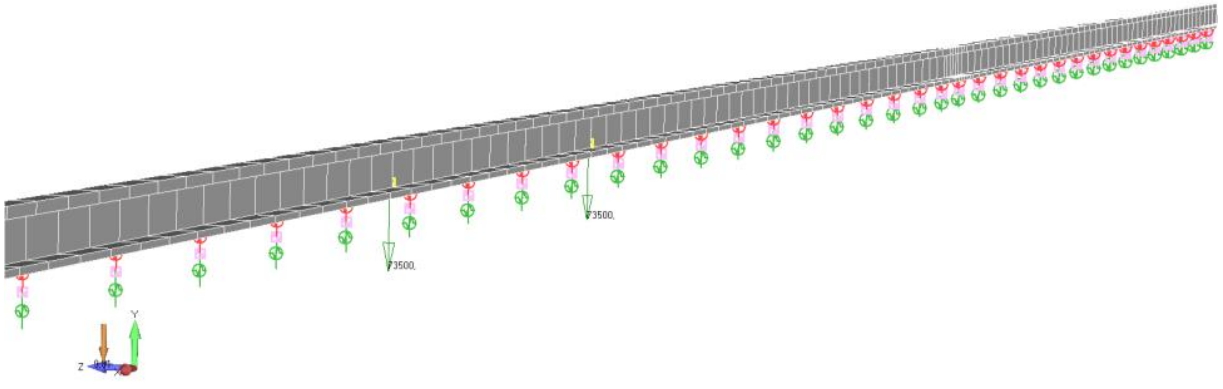

Fig. 5. Track section with booted sleepers FE-model.

The results of static analysis coincide well with the rail deflection measurements, performed in the Moscow underground. The analysis shows, that the track deflection with LVT-M booted sleeper is 1,02 $\mathrm{mm}$ and with LVT-HA booted sleeper - 1,94 $\mathrm{mm}$.

Modal analysis results for the track with LVT-M booted sleepers are shown in Figure 6.

a) $48,0 \mathrm{~Hz}$

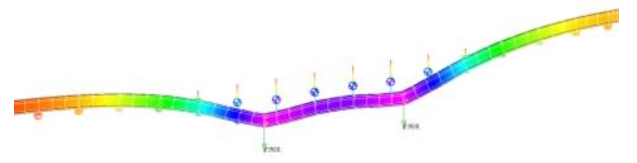

b) $58,8 \mathrm{~Hz}$

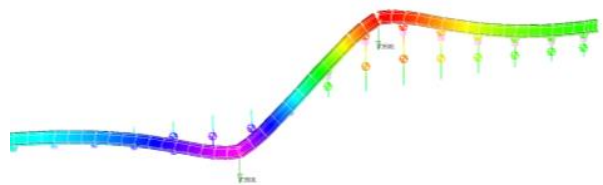

c) $82,7 \mathrm{~Hz}$

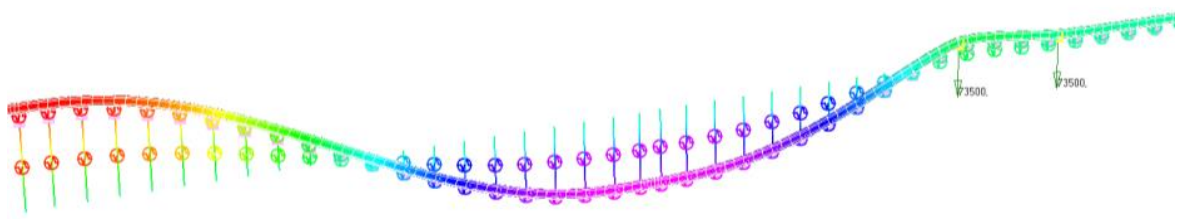

Fig. 6. Track with LVT-M booted sleepers modal analysis results.

The first bending mode frequency of the track with LVT-M booted sleeper is $48 \mathrm{~Hz}$ and $30,7 \mathrm{~Hz}$ for the track with LVT-HA booted sleepers. The first bending mode frequency is $22 \%$ and $7,4 \%$ higher for the FE model than for the analytical one. This difference comes from less accurate definition of bending line length in the analytical model.

The second bending mode frequency of the track with LVT-M booted sleeper is $58,8 \mathrm{~Hz}$ and $40,5 \mathrm{~Hz}$ for the track with LVT-HA booted sleepers. The bending mode of the track without the train load is $82,7 \mathrm{~Hz}$ for the LVT-M booted sleeper and $49,9 \mathrm{~Hz}$ for the LVTHA. These values can be used to verify the dynamic properties of the track superstructure with the experimental results, obtained from direct modal measurements in tunnel.

\section{Conclusion}

This paper presents results of the track with vibration isolated booted sleepers' dynamic analysis. An analytical model for vertical track deflection is derived from the Winkler beam model on elastic foundation, which is adopted to the case of booted sleepers with elastic railpad and undersleeper pad application. A FE-model of the track structure is created in MSC Nastran/Patran commercial package, that simulates all relevant for the analysis track (stiffness, damping and rigid properties of rails, sleepers and elastic pads) and vehicle (axle 
load, unsprung mass weight) parameters. Both static and modal analysis of the track structure is performed and compared with field measurements, which shows good coincidence between the results, that confirms the model validity and accuracy.

Modal analysis results show first bending frequencies for both track structures. Depending on the first bending mode frequency the effective vibration isolation region can be evaluated, which starts from $82 \mathrm{~Hz}$ and $57 \mathrm{~Hz}$ for the track with LVT-M and LVT-HA booted sleepers, respectively.

This work was financially supported by Ministry of Education and Science of the Russian Federation (\#NSh-3492.2018.8).

\section{References}

1. V. Smirnov, I. Tsukernikov. Proc. Eng. 176, 371 - 380, (2017)

2. I. Tsukernikov, V. Smirnov, I. Shubin, T. Nevenchennaja. ICSV 2017

3. Bahrekazemi M. Train-induced ground vibration and its prediction. (Royal Institute of Technology, Stockholm, Sweden, 2004)

4. T. X Wu. Acoustics 08, 1783 - 1787 (2008)

5. J. T. Nelson, Journal of Sound and Vibration 193, 367-376 (1996)

6. Marschnig S and Veit P. Int Railway J. 52, 27-30 (2011)

7. Loy H. Eur Railway Rev. 4, 46-51 (2008)

8. Loy H. Railway Tech Rev. 2, 35-38 (2009)

9. Witt S. The influence of under sleeper pads on railway track dynamics. (Licentiate Thesis, Linkoping University, Sweden, 2008)

10. S. Kaewunruen, A.M. Remennikov. Proc. of the 13th Int. R. Eng. Conf., 1-17 (2015)

11. P. Ruge, C. Birk. Journal of Sound and Vibration, 304, 932 (2007)

12. LVT. Vibration attenuation report. Doc. no DPD078.GN. Sonneville, 2011 